\title{
BMJ Open Barriers and facilitators to staying in work after stroke: insight from an online forum
}

\author{
Chantal Balasooriya-Smeekens, ${ }^{1}$ Andrew Bateman, ${ }^{2}$ Jonathan Mant, ${ }^{1}$ \\ Anna De Simoni ${ }^{3}$
}

To cite: BalasooriyaSmeekens C, Bateman A, Mant J, et al. Barriers and facilitators to staying in work after stroke: insight from an online forum. BMJ Open 2016;6:e009974. doi:10.1136/bmjopen-2015009974

- Prepublication history for this paper is available online. To view these files please visit the journal online (http://dx.doi.org/10.1136/ bmjopen-2015-009974).

Received 14 September 2015 Revised 1 February 2016 Accepted 2 February 2016

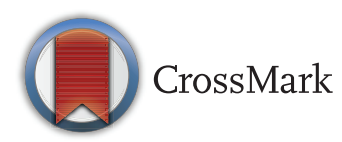

\footnotetext{
${ }^{1}$ The Primary Care Unit, Department of Public Health and Primary Care, University of Cambridge, Cambridge, UK

${ }^{2}$ The Oliver Zangwill Centre, The Princess of Wales Hospital, Ely,

Cambridgeshire, UK

${ }^{3}$ Centre for Primary Care and Public Health, Barts and The London School of Medicine and Dentistry, Queen Mary University of London, London, UK
}

Correspondence to Dr Anna De Simoni; a.desimoni@qmul.ac.uk

\section{ABSTRACT}

Objective: To explore barriers and facilitators to staying in work following stroke.

Design: Qualitative analysis of posts regarding staying in work following stroke using the archives of an online forum for stroke survivors.

Participants: 60 stroke survivors (29 male, 23 female, 8 not stated; mean age at stroke 44 years) who have returned to work, identified using terms 'return to work' and 'back at work'.

Setting: Posts from UK stroke survivors and family members on Talkstroke, the forum of the Stroke Association, between 2004 and 2011.

Results: Stroke and transient ischaemic attack (TIA) survivors reported residual impairments that for many had impact on work. Most impairments were 'invisible', including fatigue, problems with concentration, memory and personality changes. Participants described positive (eg, back at work being better than expected) and negative work experiences, including being at risk of losing the job because of stroke-related impairments. Barriers to successfully staying in work included lack of understanding of stroke-in particular invisible impairments—of survivors, employers and general practitioners (GPs), and lack of support in terms of formal adjustments, and 'feeling supported'. Stroke survivors described how they developed their own coping strategies, and how workplace and employer helped them to stay in work.

Conclusions: Despite having been able to return to work after a stroke, people may still experience difficulties in staying in work and risking losing their job. There is a need to improve awareness, in particular of invisible stroke-related impairments, among stroke survivors, work personnel and clinicians. This might be achieved through improved assessments of residual impairments in the workplace and in general practice. Future studies should investigate the effect of unrecognised fatigue and invisible impairments on staying in work following stroke, and explore the potential role for primary care in supporting stroke survivors who have returned to employment.

\section{INTRODUCTION}

Each year 110000 people in England suffer a stroke, a quarter of whom are of working age. ${ }^{12}$ Return to work in post-stroke patients

\section{Strengths and limitations of this study}

- This is the first study that used online forum data to explore barriers and facilitators to staying in work after stroke/TIA, and complements the current evidence that is focussed mainly on returning to work.

- The study used a novel methodological approach by qualitatively analysing posts of patients on an online forum, which allowed for naturalistic data collection without involvement of a researcher.

- However, a limitation of this approach is that no follow-up questions could be asked from patients.

of working age varies greatly, with some patients not being able to return at all whereas others return successfully to their previous occupation. ${ }^{2}$ The UK's stroke strategy $^{3}$ highlighted that it is important for people who have had a stroke to participate in employment. ${ }^{4}$ Being unemployed is associated with physical and mental health problems, ${ }^{2}{ }^{6}$ while working has positive effects on the health of people with chronic conditions. $^{2}{ }^{6-8}$ A recent study estimated the cost of stroke care in UK to be $£ 9$ billion a year, of which $30 \%$ is income and productivity loss. $^{7}$ Strategies to help people successfully return to, and stay in work after stroke are therefore needed; there is, however, limited evidence on how this could best be achieved.

Most of the current evidence on barriers and facilitators to going back to work after stroke has come from work with patients who have not (yet) returned to work. In a review by Wang et at ${ }^{\ominus}$ the most important barrier to returning to work was having severe residual impairments. Facilitating factors included more years of working experience, a positive working environment, social support, acceptance of impairment or having therapy aimed at returning to work. ${ }^{9} 10$ Other studies have identified barriers such as psychological 
problems, stress, problems specific to the job or an unsupportive workplace, older age and black ethnicity. ${ }^{10-12}$ The qualitative study by Alaszewski et $a l^{11}$ included a few stroke survivors who had returned to work, who reported problems such as fatigue, difficulty with concentration and fear of a second stroke. ${ }^{11}$ Gilworth $e t a l^{13}$ explored experiences and expectations of stroke survivors in relation to returning to work. The study included some participants who had actually returned to work showing that workplace environment and patient's personality played an important role in successfully keeping their employment. Often returning to work after stroke is seen as an indicator for recovery, despite many people still needing long-term support at the workplace. ${ }^{14}$ Evidence for this has been reported in the review by Wolfenden and Grace ${ }^{14}$ who showed that between $13 \%$ and $32 \%$ of people with a brain injury drop out of work after having resumed employment. In addition to factors affecting return to work, more attention should be paid to issues related to staying in work. ${ }^{14}$

Occupational health services are variable across the UK. Only few small or medium-size organisations have services, whereas large employers have their own occupational services. ${ }^{15}$ Guidelines focus largely on successfully returning to work. Although long-term monitoring of people (including those who have returned to work) has been advised, ${ }^{15}$ evidence on barriers and facilitators of staying in work is rather limited. Further in-depth exploration of people's short-term and long-term experiences after returning to work is important.

Internet and social media are increasingly accessed by patients and their caregivers as a way to get information, discuss needs and provide and receive support. ${ }^{16}$ Online forum data are generated without involvement and influence of a researcher, thus 'naturally' created between people taking part in the discussions on the forum. Posts are likely to closely reflect the issues relevant to the particular population and not reflect the researchers' agenda. ${ }^{17} 18$

\section{Aim}

Our aim was to explore the experiences of people who have returned to work after a stroke by analysing the archives of an online forum. We aimed to understand whether people who have returned to work were still experiencing stroke related difficulties, as well as exploring what helped them retaining their job over time.

\section{METHODS}

\section{Design}

We conducted a qualitative analysis of stroke survivors' posts on a web forum. We included posts about work written by stroke survivors who had returned to work, and by people posting about stroke survivors who had returned to work.

\section{Setting}

We conducted our analysis using the archives from TalkStroke Online, a UK based online forum hosted by the Stroke Association website and dated between 2004 and 2011. Talkstroke is an online web forum used by stroke survivors and as well as third parties (mostly partners and family members of stroke survivors) to share their stories, and give and receive information and support.

\section{Ethics}

The Stroke Association handed over the archives to ADS and gave permission to use the data for research purposes. People signing up to Talkstroke agreed that their data were public on registration on the forum. To protect the identity and intellectual property of forum participants, we chose not to use quotes, ${ }^{19}$ despite this being normal practice in qualitative research. Instead, we used descriptions of quotes throughout the text.

\section{Identification of study participants}

In total, there were 22173 posts in the archives of the forum, and 2583 unique usernames. To be able to identify relevant posts we searched the archives for the phrase 'return to work', through which we identified 31 people who posted about returning to work, and for 'back at work', which led to an additional 29 people.

\section{Analysis}

We analysed the posts using thematic analysis as described by Braun and Clarke. ${ }^{20}$ Two authors (CBS and ADS) read through all posts (including those not about work) from the 60 individuals included, to get familiar with the data and peoples' stories, and to identify characteristics from stroke survivors including demographics, information of stroke type and residual impairments. Social class was determined using the SOC2010 and NS-SEC Occupation coding tool. ${ }^{21}$ One author (CBS) selected the posts about work from the 60 participants, and analysed those using NVivo9. Posts were coded for barriers and facilitators of staying in work after stroke. An initial coding framework was developed, which was adjusted as new data were added. This was initially done for the first 31 individuals, and then again for the additional 29 individuals as data saturation on themes had not been reached within the first set of individuals. Saturation of data for unique themes was reached within the data of these 29 individuals, and therefore no further people and posts were selected. Coding was then performed independently by a second author (ADS) for 15 participants. Coding was discussed until agreement was reached, and the coding framework and coding for the other 45 participants was revised as well.

\section{RESULTS}

Characteristics of stroke survivors included in the study Sixty participants were included in the study, 51 were stroke survivors who posted on the forum themselves, while the remaining nine stroke survivors were posted 
about by family members. Both sexes were represented and median age was 44.5, ranging from 25 to 66 (table 1). Most people had a stroke, but some included in the study had a transient ischaemic attack (TIA). Most people returned to work between 3 and 6 months after their stroke, although time-lapse before returning to work varied greatly and was not described by half of the sample. All people, including the ones who experienced a TIA, described suffering from residual impairments that impacted on their working life. Impairments included fatigue, epilepsy, pain, psychological and cognitive problems. Only some had visible impairments, including walking difficulties and speech problems.

\section{Themes}

We found a wide range of barriers and facilitators of staying in work from the stroke survivors and carers perspectives, which are shown in table 2. Findings will be discussed within the three themes below:

1. Understanding stroke

A very important reason for people having difficulties at work, or even being at risk of losing their job, was having invisible impairments. Invisibility of impairments often led to a lack of understanding as they are not immediately obvious, in particular by the employer but also the general practitioner (GP) and stroke survivor themselves. If impairments or stroke were more visible, it was usually easier for other people as well as the patients themselves to understand their difficulties. The understanding and knowledge about stroke and stroke-related impairments among employers, as well as patients themselves and others such as GPs is very important to staying in work, as well as to receiving appropriate support from employers and GPs.

\section{Support}

Support from others, in the form of formal adjustments at work, or making patients feel understood, was important to staying in work. Usually, employers who better understood the stroke-related problems were more supportive. However, people also described occasions in which they felt bullied, or others were making jokes about them. A main finding is that the invisibility of impairments greatly affects people's understanding of stroke, and as a result the support received, which may affect their ability to stay in work.

3. Impairments and recovery

A range of impairments were described as reasons for not being able to staying in work, or for having difficulties at the workplace. Sometimes problems were brought on by being back at work. Medical interventions such as physiotherapy, and support from family members or GPs helped general recovery and therefore helped people successfully maintaining employment. Being able to cope with these impairments had a positive effect on work. There were also various indirect issues related to recovery that made working difficult (such as not being able to drive, or stress at work bringing on problems).
The findings did not seem to differ between people who suffered a stroke and TIA-people with a TIA also reported residual impairments and difficulties at the workplace. Moreover, people with invisible impairments and those with visible and invisible impairments did not seem to differ clearly in the way these issues were experienced (however, all individuals had invisible impairments to some extent). No particular differences were found regarding job type and time of returning to work, although these data were missing for quite a large part of the sample.

\section{Understanding stroke \\ Invisibility of impairments and misunderstanding}

All individuals reported invisible impairments to some extent, of which the most common was fatigue (table 2 , 1a). Other invisible impairments that were described included cognitive impairments such as memory problems, personality changes and pain. People described that having an invisible impairment often led to misunderstanding, in particular by the employer but also the GP, as well as by the person themselves (table 2, 1d). The lack of visibility of the impairment or the fact that they were lasting beyond the planned period of phased return to work led to stroke survivors being perceived as 'making up' their problems, being lazy, too often sick and underperforming. This caused a lot of frustration to the forum users. In a few cases, this even led to the risk of losing the job. "A man shared his experience that his boss tells him that he is being lazy, and that he cannot blame the stroke anymore for not having motivation for work. (Male, 43, age at stroke 43 , stroke type not stated, job type not stated, N42)".

Two people described their GPs lack of understanding about their stroke-related problems (table 2, 1d). "One person described that she thinks that, except for people who have experienced a stroke, no one understands the consequences of stroke, and her GP definitely does not understand it either. (Female, 50, age at stroke 47, stroke, office/professional job, N3)".

\section{Normality}

Having invisible impairments was sometimes described by patients in relation to normality, as looking normal but not feeling normal. The contrast between looking and sounding normal from the outside and the presence of fatigue and other invisible impairments often led to difficulties, and a lack of understanding by others (table 2, 1a, b, d); others could not see anything different to how people were before the stroke, and therefore treated them in the same way as usual. "A wife of a stroke survivor wrote that it was frustrating that workmates were treating her husband in the same way as before his, as if he was fully recovered (Male, 49, age at stroke 49, stroke type not stated, job not stated, written by carer, N51)".

Invisibility of problems also caused difficulties for patients themselves, and some felt they should be back to 'normal' because they looked normal, but were not able to work as before because of invisible impairments 
Table 1 Characteristics of the Talkstroke online participants as identified in the posts

\begin{tabular}{|c|c|c|}
\hline Sample characteristics & $\mathbf{N}$ & Median (range) \\
\hline Total number of participants & 60 & \\
\hline Age at stroke & 44 & $44.5(25-66)$ \\
\hline \multicolumn{3}{|l|}{ Participants' posts } \\
\hline Number of posts on the forum/participant & & $8(1-305)$ \\
\hline Number of posts about work/participant & & $2(1-27)$ \\
\hline \multicolumn{3}{|l|}{ Identity person posting } \\
\hline Stroke survivor & 51 & \\
\hline Carer & 9 & \\
\hline \multicolumn{3}{|l|}{ Gender of stroke survivor } \\
\hline Male & 29 & \\
\hline Female & 23 & \\
\hline Not stated & 8 & \\
\hline \multicolumn{3}{|l|}{ Earliest returned to work } \\
\hline Immediately-up to 3 months & 8 & \\
\hline 3 months-up to 6 months & 9 & \\
\hline 6 months-up to 12 months & 6 & \\
\hline $1-2$ years & 7 & \\
\hline Over 2 years & 1 & \\
\hline Not stated & 29 & \\
\hline \multicolumn{3}{|l|}{ Type of job§ } \\
\hline \multicolumn{3}{|l|}{1 Higher managerial, administrative and professional occupations } \\
\hline 1.1 Large employers and higher managerial and administrative occupations & 0 & \\
\hline 1.2 Higher professional occupations & 2 & \\
\hline 2 Lower managerial, administrative and professional occupations & 15 & \\
\hline 3 Intermediate occupations & 12 & \\
\hline 4 Small employers and own account workers & 1 & \\
\hline 5 Lower supervisory and technical occupations & 0 & \\
\hline 6 Semi-routine occupations & 4 & \\
\hline 7 Routine occupations & 1 & \\
\hline 8 Never worked and long-term unemployed & 0 & \\
\hline 9 Other (eg, more than 1 job/category) & 2 & \\
\hline Not stated & 23 & \\
\hline \multicolumn{3}{|l|}{ Type of stroke } \\
\hline Ischemic & 11 & \\
\hline Haemorrhagic & 4 & \\
\hline Stroke (unspecified) & 19 & \\
\hline TIA & 5 & \\
\hline Not stated & 21 & \\
\hline \multicolumn{3}{|l|}{ Residual impairments } \\
\hline Only visible* & 0 & \\
\hline Both visible and invisiblet & 16 & \\
\hline Invisible & 37 & \\
\hline Unknown & 5 & \\
\hline \multicolumn{3}{|l|}{ Specific residual impairments $\ddagger$} \\
\hline Tiredness and fatigue & 29 & \\
\hline Walking difficulties, balance and coordination problems & 9 & \\
\hline Pain and headaches & 11 & \\
\hline Weakness, coldness, stiffness, shaking or numbness in body parts (eg, in hands) & 20 & \\
\hline Psychological or emotional difficulties (incl. depression, personality changes, emotional, confidence) & 22 & \\
\hline Cognitive problems (incl. memory, concentration, multitasking) & 16 & \\
\hline Language problems (eg, speaking, listening, reading, writing) & 12 & \\
\hline Vision difficulties (eg, side vision) & 5 & \\
\hline Otherף & 22 & \\
\hline
\end{tabular}

*This includes physical problems such as walking difficulties (even if minor), mobility (including movement of arms or legs), balance and coordination issues, changes in the face, and speech problems. This categorisation is done by the researchers, and is based on what is reported in the data.

tInvisible disabilities include cognitive and psychological difficulties, but also issues such as hearing problems or pain. This categorisation is done by the researchers, and is based on what is reported in the data.

‡List is not exhaustive. Further, people could have reported more than one impairment.

IAll impairments and problems below $n=5$. (these include being 'slow' in the morning, feeling lightheaded, Hughes Syndrome, nausea or dizzy spells, dribbling or droop in face, epilepsy, sleeping difficulties, hearing problem, feeling easily 'overloaded').

$\S$ The SOC2010 and NS-SEC Occupation coding tool ${ }^{21}$ was used.

TIA, transient ischaemic attack. 
Table 2 Themes, divided in barriers and facilitators in retaining work among people who have returned to work: findings from the Talkstroke online webforum

\begin{tabular}{lll}
\hline (Sub) themes $\quad$ Barriers & Facilitators \\
\hline 1. Understanding
\end{tabular}

1. Understanding stroke 1a. Visibility

1b. Normality

1c. Sharing situation with others 1d. Knowledge of
stroke

1e. Expectations and self-awareness

\section{1f. Acceptance}

2a. Strategies in the workplace
- Disabilities that are not visible to other people (eg, fatigue, cognitive problems)

- Others (ie, colleagues, employer) thinking that the patient is making up the problems

- Feeling a fraud when having invisible problems, or problems that the patient sees as relatively 'minor' (and therefore apprehension in sharing problems with others at the workplace)

- Looking normal, not feeling or being normal (leading to a lack of understanding of a person's difficulties)

- Acting normal (others not being aware of difficulties, and in some cases being more tired by trying to 'keep up')

- Not wanting to share stroke-related difficulties with others at work (resulting in less understanding of the patients' difficulties)

- Embarrassment regarding sharing problems with other people

- A lack of understanding of stroke and stroke-related problems, or the timeframe of recovery (by patients and employers)

- GPs lack of understanding of the patients' problems

- Returning to work too soon, or taking on too much at work

- Lack of self-awareness, returning against the advice of others, or underestimating own disabilities, (ie, being unaware of making mistakes)

- Being back at work is more difficult than anticipated

- Problems getting worse after returning to work

- Overestimation of own disabilities, or potential difficulties related to work

- Pushing oneself (ie, not accepting a changed identity, and that one cannot function like before $\mathrm{TIA} /$ stroke)

Problems with following the right steps towards making adjustments (eg, not talking to Occupational Health)
- Having had a stroke at the workplace (increased visibility, and as a result patients' experience of support and understanding at the workplace)

- Wanting to be normal and return to work, work acting as a motivator to recovery

Talking with employer about difficulties, and the adjustments that are needed

- (Improvement of) employers' understanding of stroke and stroke-related problems

- Patients' understanding of problems and their ability to cope with them (table 2.)

- The anticipation of difficulties at work, and making appropriate arrangements related to this (ie, coping by the patient, as well as strategies in the workplace)

- Accepting that one cannot function like before TIA/stroke, needs more rest, has to listen to his our her body

- Priorities changed, and re-labelling of one's identity (ie, work now seen as less important)

- Range of strategies incorporated: Adjustments to the workplace, gradual return, reduced hours or duties, taking time, working at home, going home if tired

- Occupational Health appointment

- Changed the job for a job that was manageable

- Union involvement (to keep a job)

- Employer expecting a return to work

- Patient following the appropriate steps at work (Occupational Health, HR)

2b. Support from others
- Lack of support and at work, by the employer or by colleagues (patient not feeling understood, and in some cases resulting in job loss)
Having a supportive and patient employer, having supporting colleagues

- Supportive family and friends

- Advice and support from others with stroke (ie, the Talkstroke Online forum, stroke club) 
Table 2 Continued

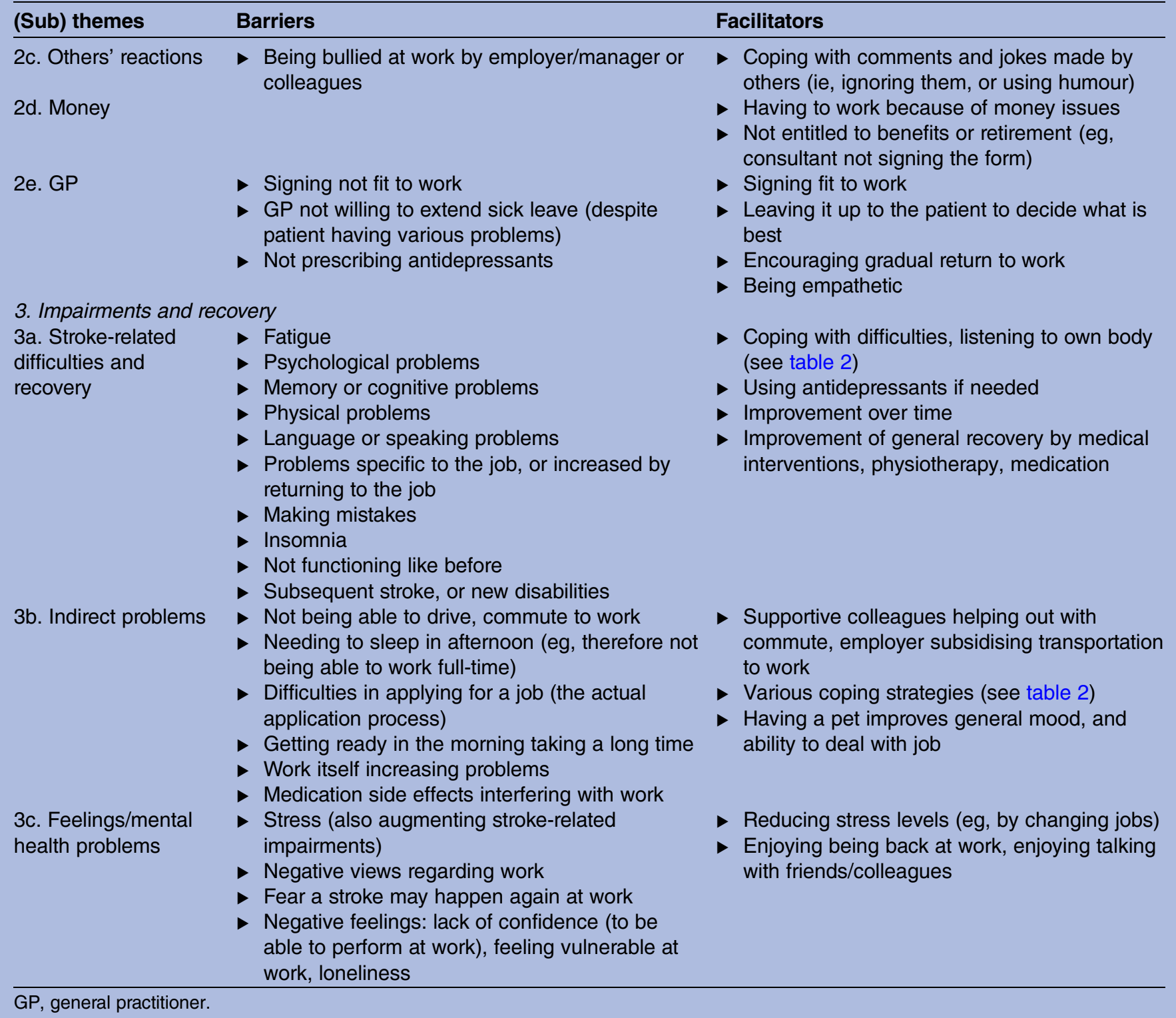

(table 2, 1a, b). One person wrote that he was feeling a fraud. "A person discusses that at on the one hand, he experienced something life-changing with long lasting consequences, whereas on the other hand, he feels a fraud, because he did not have major (visible) impairments (Male, 61, age at stroke 61 , stroke, office/professional job, N28)".

Some people described that they were trying to act normal, although the 'denial' of problems led to difficulties; when people pushed themselves too hard, this became a barrier to staying in work (table 2, 1f). Although the contrast between looking normal, but not feeling normal usually caused difficulties from the patient and others' perspectives, there were a few people whose goal to return to work to go 'back to normal' led to a positive work experience (table 2, 1b). However, realistically accepting the situation and adjusting accordingly were important factors in successfully 'staying in work' experience (table 2 , 1f, see also box 1 , coping strategies).

\section{Fatigue: a common invisible impairment}

The most important invisible impairment causing difficulties at work was fatigue. More than half of people described fatigue in their posts, and some described how fatigue affected their productivity at work, or that needing to rest after work affected their day-to-day activities. "A woman described that she tries to keep her part-time job, but that she feels sore and fatigued, and needs to sleep after getting home. She has to stay in bed the rest of the day, until her husband comes home and cares for her. (Female, age at stroke and current age not stated, stroke, office/professional job, N13)" (table 2, 1a).

Several people described difficulties they had understanding the impact of fatigue, and how it was brought on by stress and day-to-day work (table 2, 1a, d, e). " $A$ stroke survivor wrote about how he did not realise what stroke-related fatigue was, until he quit his job and felt better, and talked to an occupational therapist after he could make 
more sense of how he felt (Male, 50, age at stroke 47, stroke, office/professional job, N19)".

The impact of fatigue was sometimes greater than people had originally anticipated, in particular if they had suffered a TIA, as people were supposed to only have temporary problems as a result of a TIA (table $2,1 \mathrm{e}$ ). " $A$ man who had a TIA described that, after returning to work, he was surprised that he felt so exhausted. He then realised that he was still having problems (Male, 46, age at stroke 45, TIA, office/professional job, N59)".

\section{Impairments becoming 'visible'}

Four people described having their stroke at the workplace. One of them said that their stroke became 'visible' to others because it happened at the workplace, and suggested that this helped being supported and understood by the employer and colleagues despite 'invisible' impairments. "A woman wrote that her employer has been very understanding, which she thought may have been because she has had her stroke in front of everyone at work (Female, 51, age at stroke 51, stroke, office/professional job, N20)" (table 2, 1a).

A few people did not want to share their stroke-related difficulties with their employer, or felt embarrassed about sharing their problems with others (table 2, 1c). This created interpersonal problems and acted as a barrier, as impairments were not disclosed. People around them could therefore not be aware of the extent of the difficulties the stroke survivor was experiencing and could not be supportive. "A woman wrote that her husband had a stroke, and was recovering well. He returned to work part-time, but was still having difficulties with writing. He was able to hold a pen, but could not write in the way he wanted to. She said he felt embarrassed about it, and was reluctant to ask the health and safety team for support. (Male, 38, age at stroke 38, stroke, office/professional job, written by carer, N37)".

\section{Support}

Support, in the form of formal adjustments as well as 'feeling' supported, was an important facilitator in retaining work (table 2, 2a, b). Having an employer who was patient and supportive helped the person ease back into work. Talking with the employer about problems and with Human Resources and Occupational Health helped create a supportive environment, through increasing all parties' awareness of stroke-related impairments, especially the non-apparent ones. This also made it possible to make appropriate work adjustments. For most stroke survivors, adjustments were gradual return, reduced hours and working at home. "One person describes that no appropriate adjustments were made. He looked the same as before, and even though he told his employer about his problems, they never offered him help. His productivity declined, and he went to the GP for advice, who told him to talk to HR. Although he did have an Occupational Health assessment, he felt that no adjustments were made he was expected to function as usual, and he was at risk of losing his job. (Male, 41, age at stroke 37, stroke, office/professional job, N15)".
Understanding of stroke-related impairments was closely related to support. After learning more about stroke and impairments of an employee, an initially 'difficult' employer changed his attitude and supported his employee better (table 2, 1d, 2a, b). "A man reported that his manager was initially not good at communicating and understanding him, however, after he heard at the assessment about the problems he was having, he became much more understanding and supportive. (Male, 61, age at stroke 61, stroke, office/professional job, N28)".

However, being supportive also varied person to person, and change in management personnel affected the ability of staying in work. One person was back at work for a long time, with an understanding manager. The arrival of a new manager unaware of the person's stroke-related impairments lead to the employee being bullied. He/she described considering leaving the job. When employers were not being supportive (eg, by not making suitable adjustments, or not believing the person's problems), stroke survivors suffered great distress, in particular when feeling they were at risk of losing their job. Another person described how it became too difficult to deal with an unsupportive, bullying employer and considered early retirement. Others felt they were bullied by colleagues, and although they usually coped with this by ignoring them, or making jokes, it affected them negatively (table $2,2 b, c)$.

\section{The GP's role}

The role or support from the GP was not commonly mentioned, but mostly in the context of writing or not writing sick notes. Experiences with the GP writing sick notes varied. One person mentioned that her GP was supportive and let her decide when she felt ready to return to work. "She wrote that her GP said that it was up to her when she was ready to return to work. She then went back to work after 8 weeks. (Female, 52, age at stroke 51, stroke, office/professional job, N24)" (table 2, 2e).

Another person felt upset because he felt that the GP did not seem to consider the problems the person was having and did not want to write a sick note. "He described that the GP was not willing to extend the sick leave, as the GP thought he was fit enough to return to work, even with impairments such as walking problems, communication problems, limb spasms and fatigue, because he could sit at a desk and could move all limbs. (Male, 61, age at stroke 61, stroke, office/professional job, N28)".

In only two cases, a person received advice from the GP about returning to work. "A woman said that her GP advised her to return to work on reduced hours. (Female, 39, age at stroke 39, stroke, job not stated, N58)".

\section{Impairments and recovery}

\section{Stroke-related impairments and recovery}

Stroke survivors did experience a wide range of visible and invisible impairments (including but not limited to physical, psychological, language and cognitive) that affected to some extend their performance or staying in 
Box 1 Strategies as described by participants in dealing with work, staying in work, or problems at work or related to work

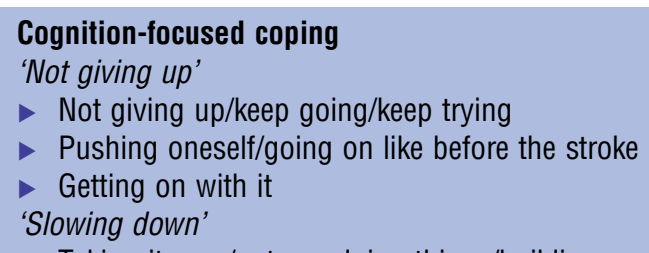

- Taking it easy/not overdoing things/building up gradually

- Working slower than before/take it slowly

- Not pushing oneself/be kind to oneself

- Pacing oneself/taking one day a time/doing a little bit every day

'Accepting change'

- Acceptance (eg, of the impairments, of the new self, or the new situation)

- Listen to body

- Be positive

- Being patient

- Be prepared for bad days

'Thoughts'

- Thinking about stroke survivors in worse situations

- Not thinking about the problem

- Back to work as a way to forget/to be 'normal'

- Thinking of what one can do instead of cannot do

Action-focused coping

Dealing with fatigue

- Learning about fatigue

- Learning how to manage fatigue

- Taking naps/going to bed early

- Exercise to fight tiredness

Dealing with stroke-related problems

- Asking work colleagues for help with mobility

- Asking work colleagues for help with communication

- Using voice recognition software

- Proofreading/using spelling check

- Taking breaks at work (eg, to deal with background noise)

- Reducing travel to work (eg, by staying overnight at parents' house which is nearer to work)

- Practicing driving before return to work

- Taking antidepressant to improve confidence at work

- Planning in advance and in detail how to fix a problem at work

- Concentrating when moving the weak side of the body at work

Dealing with other people

- Providing explanations to others (about being different than before stroke, especially about 'invisible' impairments)

- Using humour when dealing with negative comments

- Give employer information about stroke, especially about 'invisible' impairments

- Ignore people who are making negative comments/making fun

- Thinking about what to say (as a reply to potential comments) before meeting colleagues

Getting support/advice

- Setting up a young stroke group to get support

- Reading the Stroke Association website for advice helps recovery

General

- Making changes in lifestyle

- Going back to work as a way to improve recovery and satisfaction

- Not working excessively

- Setting goals

- Keeping active

- Expecting and accepting physical difficulties, and not doing too much too soon

Some elements mentioned here may additionally appear in table 2. The aim of box 1 is to offer to the readers and stakeholders (patients, carers, employers and representatives, GPs and Occupational Therapists) strategies that have been distilled over time and with efforts by those patients who managed to endure the process of returning and staying in work.

These are descriptions of actual quotes - they have been paraphrased to respect the identity and intellectual property of forum participants (see Ethics section in the Methods). 
work, for example "a man who explained that he realised he could not do his job (machinery setter) anymore physically and mentally, and was interested in receiving training to do a different job. (Male, 32, age at stroke 32, stroke, manual job, N16)" (table 2, 3a).

Some people described their problems that affected specific aspects of their job. "A woman described a situation in which she was talking to a customer, and she could not get her words out. Her secretary had to take over the conversation, and she could not function well afterwards as she was shaky and tired. (Female, 48, age at stroke 46, stroke, selfemployed, N25)".

In some cases, problems were brought on by being back at work, and people did not realise the extent of their problems before returning. "The wife of a stroke survivor described how her husband did not think that he still had major problems, however, trying to do things like before the stroke (computer work) made him realise that his problems were more severe than he previously thought (Male, 54, age at stroke 52, stroke, manual job, written by carer, N21)".

Stress was described as a source of greater difficulties than before stroke, and sometimes worsened stroke-related impairments (eg, fatigue and pains). Reducing stress helped people being able to stay in work, although it meant for some having to change jobs to reduce the stress (table 2, 3c). "Someone with his own company described having gone back to work, but realised he could now only work part-time and was getting strange feelings in arms and legs when he was stressed. (Male, 59, age at stroke 56, stroke, self-employed, N32)".

Rehabilitation and medical interventions such as physiotherapy did help people in their general recovery, and as a result improved their ability to stay in work. A few people reported that there was improvement over time (table 2, 3a). "This person described having a weak left arm and that it was only possible to type with one hand, which did not go very well. About a month later the person could type with both hands again, almost up to the level as before the stroke, to explain that things can improve over time. (Male, 61, age at stroke 61, stroke, office/professional job, N28)".

\section{Indirect problems affecting return to work}

Various other issues indirectly related to work affected successfully staying in work, including not being able to drive, needing to sleep a lot, and needing a long time to get ready in the morning. Having not enough money, especially if not entitled to benefits or retirement, was an important reason for people to keep working, even though it proved difficult for them (table 2, 2d, 3b). " $A$ woman wrote that her husband was having a difficult time with his full-time work. It would have been better if he had more time at home, however, he had no choice but to go back to work as they have little financial support. Apart from tax credit, they did not get anything because they were self-employed. They only had some statutory sick pay from a previous part-time job. (Male, 54, age at stroke 52, stroke, manual job, written by carer, N21)".

\section{Coping with impairments}

If people were able to cope with their impairments, this sometimes led to a more positive experience at work. Some people reported that once they had accepted their changed abilities, and 'listened to their body', paced their work, or were 'patient with themselves', it became easier to deal with their impairments and day-to-day activities. Several people describe how if they pushed themselves and overdid it, they felt worse later. However, at the same time people advised others on the forum to keep trying, and in a few occasions push oneself. "A woman explained that with time she started to feel more like the person she was before stroke, but that she still tended to overdo things, which had consequences the next day. She drove her son back to university, and found the long distance journey very tiring. She wrote however that she had to get used to it, as her car journey to work was also long. She was planning to go into work earlier to try the driving, and catching up on work. (Female, 46, age at stroke 45, TIA, office/professional job, N59)" (table 2, 3b).

Others developed clear strategies that they used to deal with specific problems, such as work issues, or problems related to (getting to) work, such as getting ready in the morning. Box 1 is summarising coping strategies developed by the study participants to successfully staying in work after stroke/TIA. A description of quotes has been used to protect the identity and intellectual property of forum participants (see also the Ethics section in the Methods). "A woman described that she needed to get up earlier in the morning because she had become slower after her stroke. Getting her clothes ready the night before, and having a shower in the evening was also helpful. (Female, 51, age at stroke 51, stroke, office/professional job, N20)".

\section{DISCUSSION}

\section{Findings}

This is the first study to our knowledge that used online forum data to explore barriers and facilitators to staying in work after stroke/TIA. Our findings show that many survivors, including of TIA, still experienced residual impairments, which were mostly invisible. Some participants reported impairments that led to retirement or job loss, even after a successful initial return to work. A major barrier to successfully staying in work was lack of awareness of invisible impairments from employers, staff at work, clinicians and even survivors themselves. Conversely, when awareness of stroke-related impairments and their potentially long-lasting nature was good, stroke survivors reported more positive work experiences and better support.

\section{Strengths and limitations}

A major strength of this study is the method that we used to explore barriers and facilitators to staying in work. Analysing a web forum allows for 'naturalistic' data collection without interfering with the natural process of 
data creation, which is fully done in interaction with other web forum users rather than via a researcher. ${ }^{18}{ }^{22}$ Therefore, there are less likely to be self-presentation biases, biases towards the researcher's agenda are avoided and what is discussed is truly of relevance to this particular group. ${ }^{18}{ }^{22}$ Moreover, the sample of 60 participants has been selected from 2348 participants of the forum who are younger (mean age 52 years) than the actual population of patients with stroke and in that respect representative of stroke survivors of working age. ${ }^{16}$ It remains a possibility that people taking part in the forum were better able to communicate, had less cognitive problems and higher ability in using computers in comparison to the population of patients with stroke. However, stroke survivors who are able to return to work (all our participants) may be the ones with less severe problems in comparison to those who do not return to employment, therefore representing a selected population with fewer cognitive or language problems than all survivors taken together. Further, the study included nine carers of stroke survivors talking about their relatives, potentially representing stroke survivors with more severe cognitive and language problems or difficulty with using computers. Limitations of this approach lay in lack of opportunities for in-depth exploration of specific issues, as well as lack of face-to-face insight on individuals and context participating in the study. Analysing online forums material meant that not all the relevant participant characteristics were obtained, while this would be more straightforward in traditional research like an interview study. ${ }^{22}$ Data could, however, be affected by reporting bias; people who used the forum might be the ones who wanted to voice their difficulties with returning to work. Moreover, they may have been experienced additional impairments that were not mentioned in the forum. The time frame for this study summarised postings between 2004 and 2011. Our results reflect general barriers and facilitators experienced by stroke survivors during this time frame. Technology, working environment, job market might have changed over time resulting in potentially slightly different results if the study was extended to more recent years. In addition, it is possible that experiences in 2004 differ from those in 2011 for the same reason. We were not able to analyse this, as date of posts was not available to us.

\section{Comparison with existing literature and guidelines}

Previous literature has addressed a range of factors that are important in returning to work after a stroke, including fatigue, support and work-related factors. ${ }^{9}$ In our study, we found that these were similarly affecting people staying in work. Further, almost all people in the study who recovered enough to return to work still experienced a range of residual (invisible) impairments, as suggested earlier by Alaszewski $e t a l^{11}$ and Gilworth $e t a l^{13}$ among people who had returned to work and supported by the findings of McKevitt $e t a l^{23}$ among people who were returning to work. These studies concluded that attention to long-term needs after stroke is warranted. The findings presented here should inform studies to further develop assessment tools targeted specifically at evaluating invisible stroke-related impairments in patients who have returned to work, and improve awareness of longterm recovery issues. Busch $e t a l^{12}$ found that roughly half of their participant sample that was considered fit to work did not actually return to work. The authors suggested that current assessment tools such as the Barthel Index are not suitably accurate to measure the potential of return to work, and do miss important impairments like emotional and cognitive functioning, which have an important effect on abilities of returning to work. A recent survey conducted by the Stroke Association highlighted the same issue of missing impairments with Work and Capability Assessments. ${ }^{24}$ Research exploring the potential impact of invisible impairments in returning as well as staying in work is warranted.

The 2013 National Institute of Health and Care Excellence (NICE) guidelines on stroke rehabilitation (that were published at the end of our data date range) do recognise the value of returning to work and mention impairments including invisible ones such as psychological difficulties and fatigue. ${ }^{25}$ Although the guidelines highlight the importance of making appropriate adjustments and raise awareness of the Equality Act 2010, validated assessment tools to identify invisible impairments such as memory, concentration problems and fatigue are missing, as well as information about who should be doing these assessments. The interagency guidelines recognise the issue of problems with staying in work after return to employment. ${ }^{15}$ However, most strategies to help people return to work are short-term. If long-term support is needed, advice should be sought from Jobcentre Plus DEA, Access to Work and/or a work psychologist; pathways that did not become apparent in our findings although a few had some forms of support in agreement with the statement that occupational health services vary greatly across the UK and between employers. ${ }^{15}$ When brain injury problems persist longterm, the guidelines suggest that people should be able to self-refer to appropriate services. However, although some people gave specific advice to other participants on the forum (eg, talk to your GP), we did not find overall awareness of this among our study participants. In neither of the guidelines discussed, was there a clear role for GPs, although the roles of rehabilitation and secondary care clinicians have been included. Support by GPs was not commonly mentioned on the forum, and often GPs' role in successfully staying in work was limited. The relatively minor role of primary care clinicians in supporting patients in returning to work has also been described in previous literature, and may need to be addressed. ${ }^{26}$ Although the introduction of GP fit notes in 2010 could potentially have positively affected staying in work by acknowledging specific limitations of stroke survivors at the workplace, it seemed that fit notes 
had made little impact in this study, perhaps because the fit note was at an early stage of implementation. However, it has also been suggested that GPs find it 'easiest' to sign off stroke survivors from work. ${ }^{26}$

\section{Clinical and policy implications}

We argue that awareness of stroke-related residual impairments, in particular invisible ones such as fatigue, should be improved among survivors, work personnel and clinicians. This is particularly important for people who have returned to work, as it may be assumed that such people have recovered from stroke-related impairments. This could be addressed in two ways; one through improved implementation and clarification of existing guidelines and policies and second through interventions and campaigns to improve understanding of stroke-related problems. Resuming employment can sometimes be the actual trigger of difficulties, which has the potential of affecting stroke survivors long term. Increasing awareness among stroke survivors may help them better accept stroke-related difficulties, pace their return to work and share their problems at the workplace. Making employers and working staff more aware of stroke survivors' invisible and potentially long-lasting difficulties may improve understanding, and as a result better long-term support at the workplace. The impact of invisible impairments such as fatigue can be severe and meet the definition of substantial impairment on the Equality Act 2010 and be classified as disability: "The Act defines a disabled person as a person with a impairment. A person has a impairment for the purposes of the Act if he or she has a physical or mental impairment and the impairment has a substantial and long-term adverse effect on his or her ability to carry out normal day-to-day activities". ${ }^{27}$ However, invisible impairments like fatigue are often not recognised as such by others, including employers and clinicians, as highlighted in a recent review on post-stroke fatigue by Eilertsen $e t a l^{28} \mathrm{~A}$ formal assessment of invisible impairments would contribute to making them more 'visible', and improve understanding about their (long-term) impact at the workplace. According to Radford et $a l^{29}$ and Sinclair et $a l^{30}$ awareness of such issues among clinical commissioning groups is needed, to avoid this specific group of stroke survivors with relatively mild problems 'falling through the net'. They also commented on the main commissioning focus being on acute stroke services rather than community services. ${ }^{29}{ }^{30}$ In addition to the formal rehabilitation and occupational health services, GPs could potentially play a more important role in diagnosing, managing and monitoring fatigue, cognitive and emotional problems and depression in stroke survivors who are back at work. GPs could do this by raising invisible impairments during consultations with stroke/ TIA survivors. In addition, they could use the 'may be fit' option to advise employers about the functional effects of the individual's stroke. They could also advise the individual to seek help from occupational health if it was available, or refer to the Fit for Work Service which is available to all employed patients. ${ }^{31}$ GP's support could be an important mechanism to aid successful staying in work once employment is resumed.

\section{Future research}

Future studies should investigate the effect of unrecognised fatigue and invisible impairments on staying in work following stroke. There is a need to improve awareness of stroke-related fatigue and invisible impairments among survivors, work personnel and primary care clinicians. This could be done through use of tools for recognising and assessing stroke-related fatigue and invisible impairments for use of primary care clinicians, occupational health professionals and even stroke survivors themselves. Moreover, given that impairments can be life-long or improve/deteriorate over time, a framework of assessments might be considered. Future studies are needed to further clarify how employers, GPs and community rehabilitation teams view stroke survivors returning to work, and how the various parties could work together to make employment after stroke successful. Given the promising nature of the online web forum for this patient group, ${ }^{16}$ online interventions may hold potential.

Acknowledgements The authors are grateful to the Stroke Association for sharing the archive file of Talkstroke Online with us. The authors also would like to thank Susan Brentnall, Occupational Therapist, for advice on current practice and policies.

Contributors All authors contributed to the design of the study, CBS and ADS conducted the study and analysed the data, CBS wrote the first version of the manuscript and $A D S, J M$ and $A B$ reviewed and contributed to the final manuscript.

Funding This study was funded by the Evelyn Trust (grant number 14/33). ADS is funded by a NIHR Academic Clinical Lectureship. AB was supported by the National Institute for Health Research (NIHR) Collaboration for Leadership in Applied Health Research and Care East of England at Cambridgeshire and Peterborough NHS Foundation Trust. The views expressed are those of the author(s) and not necessarily those of the NHS, the NIHR or the Department of Health.

Competing interests None declared.

Provenance and peer review Not commissioned; externally peer reviewed. Data sharing statement No additional data are available.

Open Access This is an Open Access article distributed in accordance with the Creative Commons Attribution Non Commercial (CC BY-NC 4.0) license, which permits others to distribute, remix, adapt, build upon this work noncommercially, and license their derivative works on different terms, provided the original work is properly cited and the use is non-commercial. See: http:// creativecommons.org/licenses/by-nc/4.0/

\section{REFERENCES}

1. National Audit Office. Reducing brain damage: faster access to better stroke care. London: The Stationary Office, 2005.

2. Daniel K, Wolfe CD, Busch MA, et al. What are the social consequences of stroke for working-aged adults? A systematic review. Stroke 2009;40:e431-e40.

3. Department of Health. National stroke strategy (Report no 284536): Department of Health, 2007.

4. National Institute for Health and Care Excellence. Stroke rehabilitation: long-term rehabilitation after stroke (clinical guideline CG162). Secondary Stroke rehabilitation: long-term rehabilitation 
after stroke (clinical guideline CG162). 2013. http:/guidance.nice.org. uk/CG162

5. Dworzynski K, Ritchie G, Fenu E, et al. Rehabilitation after stroke: summary of NICE guidance, 2013;346:f3615.

6. Waddell G, Burton A. Is work good for your health and well-being. Department of work and pensions. London: The Stationary Office, 2006.

7. Saka O, McGuire A, Wolfe C. Cost of stroke in the United Kingdom. Age Ageing 2009;38:27-32.

8. Department of Health. The NHS outcomes framework 2011-12. London: Department of Health, 2010.

9. Wang YC, Kapellusch J, Garg A. Important factors influencing the return to work after stroke. Work 2014;47:553-9.

10. Hartke RJ, Trierweiler R, Bode R. Critical factors related to return to work after stroke: a qualitative study. Top Stroke Rehabil 2011;18:341-51.

11. Alaszewski A, Alaszewski $\mathrm{H}$, Potter $\mathrm{J}$, et al. Working after a stroke: survivors' experiences and perceptions of barriers to and facilitators of the return to paid employment. Disabil Rehabil 2007;29:1858-69.

12. Busch MA, Coshall C, Heuschmann PU, et al. Sociodemographic differences in return to work after stroke: the South London Stroke Register (SLSR). J Neurol Neurosurg Psychiatry 2009;80:888-93.

13. Gilworth G, Phil M, Cert A, et al. Personal experiences of returning to work following stroke: An exploratory study. Work 2009;34:95-103.

14. Wolfenden B, Grace M. Returning to work after stroke: a review. Int $J$ Rehabil Res 2009;32:93-7.

15. Inter-agency advisory group on vocational rehabilitation after brain injury. Vocational assessment and rehabilitation after acquired brain injury. Inter-agency guidelines. London: Royal College of Physicians of London, 2004.

16. De Simoni A, Shanks A, Balasooriya-Smeekens C, et al. Stroke survivors and their families receive information and support on an individual basis from an online forum: descriptive analysis of a population of 2348 patients and qualitative study of a sample of participants. BMJ Open 2016;6:e010501.

17. De Simoni A, Shanks A, Mant J, et al. Making sense of patients' internet forums: a systematic method using discourse analysis. Br J Gen Pract 2014;64:e178-80.
18. Tinati R, Halford S, Carr L, et al. Big data: methodological challenges and approaches for sociological analysis. Sociology 2014;48:663-81.

19. Eysenbach G, Till JE. Ethical issues in qualitative research on internet communities. BMJ 2001;323:1103-5.

20. Braun V, Clarke V. Using thematic analysis in psychology. Qual Res Psychol 2006;3:77-101.

21. Office for National Statistics. SOC2010 and NS-SEC coding tools. Occupation coding tool. Secondary SOC2010 and NS-SEC coding tools. Occupation coding tool. 2010. http://www.ons.gov.uk/ons/ guide-method/classifications/current-standard-classifications/ soc2010/classifications-coding-tools/index.html

22. Seale C, Charteris-Black J, MacFarlane A, et al. Interviews and internet forums: a comparison of two sources of qualitative data. Qual Health Res 2010;20:595-606.

23. McKevitt C, Fudge N, Redfern J, et al. Self-reported long-term needs after stroke. Stroke 2011;42:1398-403.

24. Stroke Association. Short-changed by stroke. The financial impact of stroke on people of working age, $2012 \mathrm{https} / / / \mathrm{www}$.stroke.org.uk/ sites/default/files/short changed v4_2.pdf

25. NICE. Stroke rehabilitation. Long-term rehabilitation after stroke. NICE guidelines, 2013.

26. Coole C, Radford K, Grant M, et al. Returning to work after stroke: perspectives of employer stakeholders, a qualitative study. J Occup Rehabil 2013;23:406-18.

27. Office for Disability Issues. Equality Act 2010. Guidance on matters to be taken into account in determining questions related to the definition of disability: HM Government, 2010.

28. Eilertsen G, Ormstad H, Kirkevold M. Experiences of poststroke fatigue: qualitative meta-synthesis. J Adv Nurs 2013;69:514-25.

29. Radford K, Crompton A, Stainer K. Commissioning vocational rehabilitation after stroke: can the Cinderella services get to the ball? A qualitative study. J Health Serv Res Policy 2013;18(1 suppl):30-8.

30. Sinclair E, Radford K, Grant M, et al. Developing stroke-specific vocational rehabilitation: a soft systems analysis of current service provision. Disabil Rehabil 2014;36:409-17.

31. Department for work and pensions (2015). Fit for work. Guidance for GPs. https://www.gov.uk/government/uploads/system/uploads/ attachment data/file/458954/gp-fit-for-work-gps.pdf 